\title{
Oral cancer awareness among aged patients with chronic oral mucosal diseases in Russian Federation
}

\author{
Olga Gileva ${ }^{1, *}$, Tatiana Libik $^{1}$, Fatima Daurova $^{2}$, Olga Mudrova $^{1}$, and Tatiana Redinova ${ }^{3}$ \\ ${ }^{1}$ Perm State Medical University named after Academician E.A. Vagner, Department of Therapeutic and \\ Preclinic Dentistry, 614990, Petropavlovskaya st., 26, Perm, Russian Federation \\ ${ }^{2}$ Peoples' Friendship University of Russia, Department of Conservative Dentistry, 117198, Miklukho- \\ Maklaya st., 6, Moscow, Russian Federation \\ ${ }^{3}$ Izhevsk State Medical University, Department of Therapeutic Dentistry, 426034, Kommunarov st., \\ 281, Izhevsk, Russian Federation
}

\begin{abstract}
The secret of longevity is not only in healthy lifestyle and genetics, but in the forehanded prevention of diseases. Nowadays the preservation of health is much more the patient's responsibility. This mission can be realized only through the high level of patient's awareness and treatment compliance. Oral cancer has one of the highest mortality rates among all malignancies worldwide. A gap in patient knowledge about oral cancer, specifically related to risk factors and signs and symptoms, is posited to be among the key modifiable factor contributing to high morbidity and mortality. The purpose of this study is to evaluate the oral cancer awareness among patients of the risk group (aged patients with chronic oral mucosal diseases). Results of the study showed the lack of oral cancer awareness among patients: the mean knowledge score for the risk factors $-3,1 \pm 1,2$ out of 8,0 , for the signs and symptoms $-4,9 \pm 1,3$ out of 12,0 . It was found that women had higher oncological awareness than men, as well as participants with high educational level, and patients with premalignant oral lesions (oral lichen planus, oral leukoplakia). Educational programs are essential for improvement of oral cancer awareness among population.
\end{abstract}

\section{Introduction}

Oral health is an essential element of healthy longevity in an aging population [1-7]. Extensive evidence indicates that certain groups of oral diseases and disorders are increasing with age (e.g. coronal / root caries, extensive tooth loss, periodontal / benign oral mucosal diseases, edentulism, dry mouth / xerostomia, oral cancer, so they can be qualified as old agerelated oral pathologies [2, 8-11]. The advanced forms of age-depended oral diseases have a direct negative impact on physical, psychological, social, and economic health and wellbeing of the older persons, thereby reducing their quality of life [12-14]. Moreover, some age-related oral diseases and conditions (e.g. periodontitis, infectious oral mucosal diseases,

\footnotetext{
*Corresponding author: o.s.gileva@yandex.ru
} 
poor oral hygiene, edentulism, oral lichen planus) are regarded as an important risk factors and can adversely affect systemic health: directly via pathological pathways or indirectly via disease or therapy-related behavioural change $[15,16]$. Systemic diseases that pathogenically are associated with the diseases of oral mucosal and periodontal tissues in elderly include cardiovascular diseases, endocarditis, diabetes mellitus, Alzheimer's disease, dementia, chronic renal diseases, recurrent pneumonia, gastritis, rheumatoid arthritis, chronic obstructive pulmonary disease, and cancer [16-22]. In terms of current gerodontics, chronic inflammatory diseases of oral mucosa and its precancerous types, in particular oral erythroplakia, oral leukoplakia, oral submucous fibrosis, oral lichen planus, discoid lupus erythematous, Bowen's disease, and actinic cheilitis, represent a major threat to the health of elderly people due to high risk of malignization [23]. Up to $70 \%$ of oral cancer are preceded by premalignant oral lesions. The risk of oral precancerous lesions' malignization increases with age and achieve its maximum after 65 years old. Tobacco usage (smoked or smokeless), especially together with alcohol consumption, ultraviolet radiation, dietary deficiencies, viral (HPV, EBV, HHV-4, HHV-8, HIV, KSHV), fungal (C. albicans), bacterial (Porphyromonas gingivalis, Fusobacterium nucleatum) infections, local trauma, low socioeconomic familiar status or genetic predisposition, immune deficiency diseases and conditions (anti-cancer radiotherapy and chemotherapy), the use of nitro- and amine-containing products and drugs are well-established oncogenic risk factors for oral precancer and cancer [24-28].

Special oncological vigilance among dentists and dental patients holds a key positions in oral cancer prevention, well-timed diagnostics and treatment [7, 29, 30]. The role of dentist's professional oncological vigilance during management of patients with chronic oral mucosal diseases is obvious, while the level of oncological awareness / knowledge of the patient itself is clearly underestimated. With regard to dental patients, oncological vigilance means a set of their personal theoretical and practical activities aimed to obtain and constantly update the need-to-know knowledge in the field of oral precancer / cancer incidence and dominant risk factors in their area of residence, current state on oral cancer screening and treatment technologies (with their advantages and disadvantages), early signs and symptoms of oral mucosal lesions malignization, as well as personal patient's responsibility for prescribed therapy implementation [31].

New prospects in oral precancer / cancer prevention associated with patient's mastering of the technique for oral cancer self-screening. The recent years studies indicate the general lack of oral cancer awareness and knowledge the out-patient population in the list of top oncological problems, crucial for prevention and early detection of precancer and cancer of the mouth [32-41]. A small number of publications have been dedicated to the assessment of oral cancer awareness in high risk patients - alcohol abusers, heavy smokers etc. [42, 43]. To the best of our knowledge, there are no studies published in relation to oncological vigilance (awareness) among patients with chronic oral mucosal diseases, who are at greater risk for oral malignancies. Sociological research of this kind in Russian out-patient population has not been conducted before. Meanwhile, these data are important for areas with high rates of oropharyngeal cancer incidence, prevalence, mortality and 5-year survival rate [44]. Present study was designed to evaluate the level of oral cancer awareness among patients with chronic diseases of oral mucosa according to their knowledge of associated risk factors, signs and symptoms (early and late) of oral cancer, as well as to their possession of the oral cancer self-examination technique and its conscious application.

\section{Materials and Methods}

The study was approved by the Perm State Medical University Ethics Committee in November 2017. A cross-sectional study design was applied for the present research. Interviews with the help of the special questionnaire were conducted by doctors and post- 
graduates of the Department of Therapeutic and Preclinic Dentistry of PSMU, the Department of Conservative Dentistry of Peoples' Friendship University of Russia and the Department of Therapeutic Dentistry of IzhSMU for 24 months (January 2018 - December 2019). Only patients with chronic mucosal diseases were included to the study with their participation on a voluntary basis. The purpose of the study was explained, and written consent was received from all participants.

The 37-item questionnaire included questions helping to find out the information on socio-demographic characteristics, knowledge about oral cancer, as well as their previous experience of professional oral cancer screening. Their awareness of oral cancer was tested under three categories: (a) common knowledge (5 questions), (b) risk factors (8 questions) and (c) signs and symptoms (17 questions). The questions were in a yes/no format. The reliability of the questionnaire was analyzed using Cronbach's alpha. The completed questionnaires were collected and analyzed. Data were analyzed with the use of IBM SPSS Statistics for Windows. Descriptive statistics (for any categorical measurements: percentage and corresponding $95 \%$ confidence interval (CI); for continuous variables: mean, standard deviation, median, and range) were reported. Fisher's Exact test was performed for comparing the difference in percentages of reported (a) gender, (b) education level, (c) type of chronic mucosal disease. A p value of $\leq 0.05$ was considered statistically significant.

\section{Results and Discussion}

There were altogether 174 completed questionnaires in the study, and 7 of them were declined and not included. The reliability of the questionnaire was $0,89 \%$ (Cronbach's alpha). The participants' sample represented by $73(43,7 \%)$ males and $94(56,39 \%)$ female patients (Fig. 1). The mean age of the participants was $74.7 \pm 16.9$ years ranging from 61 to 92 years. Most of the participants had university degree $(58,08 \%)$. Only $38(22,75 \%)$ and $9(5,39 \%)$ reported to be smokers and alcohol users, respectively. The structure of oral mucosal diseases among patients was represented by oral lichen planus $(31,74 \%)$, chronic aphthous stomatitis $(17,96 \%)$, oral leukoplakia $(16,17 \%)$, glossitis including burning mouth syndrome $(10,18 \%)$, chronic trauma $(7,78 \%)$, oral candidiasis $(6,59 \%)$, oral manifestations of HPV-infection $(2,99 \%)$, precancerous lesions of the lips $(2,4 \%)$, herpetic stomatitis $(1,8 \%)$, oral mucositis $(0,6 \%)$, pemphigus vulgaris $(0,6 \%)$, erythema multiforme $(0,6 \%)$, oral discoid lupus erythematosus $(0,6 \%)$.

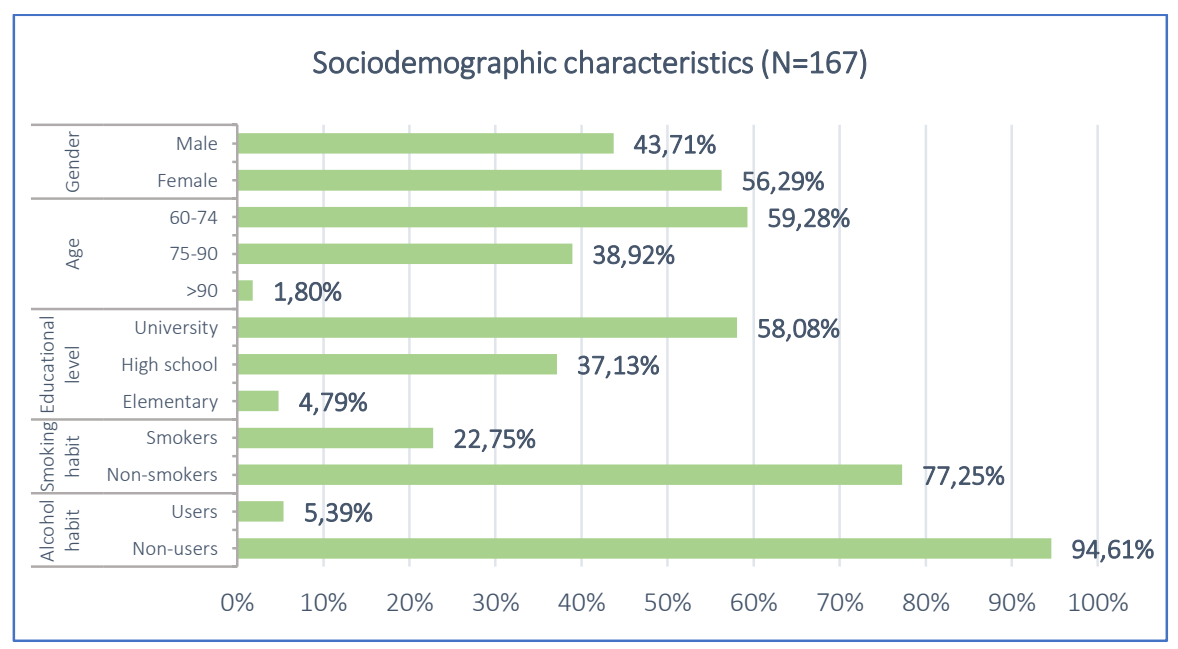

Fig. 1. Sociodemographic characteristics of the participants. 
Most of the participants knew that cancer could occur in the mouth $(96,4 \%)$, but only $35,3 \%$ knew that oral cancer can be prevented. Analysis of patients' knowledge about oral cancer risk factors showed that more obvious for them were smoking $(79,6 \%)$ and alcohol consumption $(72,4 \%)$. Nevertheless only $34,1 \%$ of patients named sun exposure as a risk factor of oral cancer. Chronic trauma and HPV-infection were identified as a risk factor only by $17,3 \%$ and $12,5 \%$, respectively. Knowledge regarding the oral cancer signs and symptoms were extremely low. The most identified symptoms were non-healing mouth ulcer $(58,7 \%)$, enlargement of cervical / submandibular lymphatic nodes $(47,9 \%)$ and unusual oral bleeding $(40,7 \%)$.

The mean knowledge scores were counted for the risk factors $(3,1 \pm 1,2$ out of 8,0$)$ and the signs and symptoms $(4,9 \pm 1,3$ out of 12,0$)$ of oral cancer. Correlation analysis of mean scores data was conducted with the connection of gender, education level and type of oral mucosal lesion (Tab. 1).

Table 1. Mean scores of risk factors knowledge and signs and symptoms knowledge

\begin{tabular}{lcc}
\multicolumn{1}{c}{ Characteristics } & $\begin{array}{c}\text { Mean knowledge score } \\
\text { Risk factors }\end{array}$ & $\begin{array}{c}\text { Signs and } \\
\text { symptoms }\end{array}$ \\
Gender & $2,3 \pm 0,9$ & $3,7 \pm 1,5$ \\
Male & $3,6 \pm 1,1^{*}$ & $6,1 \pm 2,3^{*}$ \\
Female & & \\
Age & $2,9 \pm 1,6$ & $5,2 \pm 1,2$ \\
$60-74$ & $3,0 \pm 2,2$ & $4,8 \pm 1,4$ \\
$75-90$ & $2,7 \pm 1,3$ & $4,6 \pm 1,2$ \\
$>90$ & $3,4 \pm 1,0$ & \\
Education level & $2,4 \pm 1,2$ & $6,7 \pm 1,3 *$ \\
University & $2,3 \pm 0,6$ & $4,5 \pm 0,9$ \\
High school & $3,8 \pm 1,0$ \\
Elementary & $3,7 \pm 0,8^{*}$ & $7,3 \pm 1,6^{*}$ \\
Oral mucosal disease & $2,3 \pm 0,6$ & $4,7 \pm 0,6$ \\
Oral lichen planus & $3,6 \pm 0,9^{*}$ & $6,9 \pm 1,1 *$ \\
Chronic aphthous stomatitis & $2,4 \pm 0,4$ & $4,9 \pm 0,7$ \\
Oral leukoplakia & $2,1 \pm 0,5$ & $4,1 \pm 0,9$ \\
BMS & $2,4 \pm 0,5$ & $4,3 \pm 1,1$ \\
Chronic trauma & & \\
Candidiasis & & \\
\hline 0,05 & &
\end{tabular}

It was shown that women had significantly $(\mathrm{p}<0.05)$ higher oncological awareness than men (for risk factors and signs and symptoms of oral cancer), as well as participants with university education (only for signs and symptoms of oral cancer). Also, patients with oral lichen planus and oral leukoplakia were keenly aware of oral cancer in comparison with patients with other oral mucosal diseases. There was no difference between oral cancer awareness according to the age.

Questionnaire data also brought to light the lack of oral cancer vigilance among dentists because only $5.3 \%$ of participants detected that they were examined for the presence of oral cancer, although they were in a risk group (old age and the presence of chronic oral mucosal disease). At the same time $78.4 \%$ of patients consider necessary the oral cancer screening. All participants didn't know how to perform self oral cancer screening because no one taught them, and they've never met this information in any open resources. 


\section{Conclusion}

The level of oral cancer awareness amongst patients with chronic oral mucosal diseases was perceived to be low. This included risk factors, signs, and symptoms, as well as not feel concern about oral cancer screening. The main efforts in oral cancer prevention had to be focused on bridging the gap in knowledge in patients of risk groups (aged, with chronic oral mucosal diseases, smokers etc.). Changes in public policy and action by individual dentists regarding opportunistic screening and patient oral cancer awareness during dental examinations is warranted and is an essential step for early diagnosing of oral malignancies. Public health promotion, education initiatives and awareness campaigns should be implemented on a local and national scale to increase levels of oral cancer awareness and knowledge. This will not only lead to greater awareness and knowledge amongst patients but will also improve the early detection of oral cancer amongst the population through patient self oral cancer screening.

\section{References}

1. K. Fukai, H. Ogawa, P. Hescot, Int. Dent. J., 67 Suppl 2, 3-6 (2017) doi:10.1111/idj.12347

2. P.E. Petersen, T. Yamamoto, Community Dent. Oral. Epidemiol., 33(2), 81-92 (2005) doi:10.1111/j.1600-0528.2004.00219.x

3. C. Raphael, Am. J. Public Health, 107(S1), S44-S45 (2017) doi:10.2105/AJPH.2017.303835

4. FDI World Dental Federation. Achieving a healthy ageing society. 2018. URL: https://www.fdiworlddental.org/resources/brochures/achieving-a-healthy-ageingsociety

5. Z.S. Zumsteg, G. Cook-Wiens, E. Yoshida, S.L. Shiao, N.Y. Lee, A. Mita, C. Jeon, M.T. Goodman, A.S. Ho, JAMA Oncol., 2(12), 1617-1623 (2016) doi:10.1001/jamaoncol.2016.1804

6. R. López, P.C. Smith, G. Göstemeyer, F. Schwendicke, J. Clin. Periodontol., 44 Suppl 18, S145-S152 (2017) doi:10.1111/jcpe.12683

7. O.S. Gileva, T.V. Libik, A.A. Pozdnyakova, N.V. Gibadullina, E.S. Syutkina, S.V. Korotin, Dental Forum, 72(1), 27-36 (2019)

8. P. Mojon, The world without teeth: Demographic trends. In: J.S. Feine, G.E. Carlsson, editors, Implant Overdentures: The Standard of Care for Edentulous Patients (Chicago, IL, USA: Quintes-sence, 2003)

9. W. Murray Thomson, Gerodontology, 31 Suppl 1, 9-16 (2014) doi:10.1111/ger.12085

10. S.R. Porter, C. Scully, A.M. Hegarty, Oral Surg. Oral Med. Oral Pathol. Oral Radiol. Endod., 97(1), 28-46 (2004) doi:10.1016/j.tripleo.2003.07.010

11. E.V. Serebrennikova, O.S. Gileva, Perm Medical Journal, 26(2), 129-134 (2009)

12. T. Willumsen, B. Fjaera, H. Eide, Gerodontology, 27(4), 251-257 (2010) doi:10.1111/j.1741-2358.2009.00344.x

13. D. Kandelman, P.E. Petersen, H. Ueda, Spec. Care Dentist., 28(6), 224-236 (2008) doi:10.1111/j.1754-4505.2008.00045.X

14. A.A. Pozdnyakova, O.S. Gileva, T.V. Libik, L.Ya. Satyukova, Modern problems of science and education, 2, 77 (2013)

15. C. Dörfer, C. Benz, J. Aida, G. Campard, Int. Dent. J., 67 Suppl 2, 14-18 (2017) doi:10.1111/idj.12360

16. O.S. Gileva, Maestro stomatologii, 60(4), 17-23 (2015)

17. K.H. Lee, Y.Y. Choi, Sci. Rep., 9, 14407 (2019) URL: https://doi.org/10.1038/s41598019-50863-0 
18. S.G. Yao, J.B. Fine, Dent. Open J., 5(2), 34-40 (2018) doi: 10.17140/DOJ-5-140

19. H. Akar, G.C. Akar, J.J. Carrero, P. Stenvinkel, B. Lindholm, Clin. J. Am. Soc. Nephrol., 6(1), 218-226 (2011) doi:10.2215/CJN.05470610

20. C. Scully, R.L. Ettinger, J. Am. Dent. Assoc., 138 Suppl., 7S-14S (2007) doi:10.14219/jada.archive.2007.0359

21. R.I. Garcia, M.M. Henshaw, E.A. Krall, Periodontol. 2000, 25, 21-36 (2001) doi:10.1034/j.1600-0757.2001.22250103.x

22. O.S. Gileva, E.N. Smirnova, A.A. Pozdnyakova, T.V. Libik, RMJ, 20, 1340-1345 (2016)

23. O.S. Gileva, T.V. Libik, K.V. Danilov, AIP Conference Proceedings, 1760, 020019 (2016) URL: https://doi.org/10.1063/1.4960238

24. T.V. Libik, O.S. Gileva, K.V. Danilov, S.S. Grigoriev, A.A. Pozdnyakova, AIP Conference Proceedings, 1882, 020044 (2017) URL: https://doi.org/10.1063/1.5001623

25. O. Gileva, T. Libik, E. Khalilayeva, Y. Gulyaeva, O. Khalyavina, R. Podgornii, Oral Diseases, 14(S1), 24 (2008)

26. O.S. Gileva, Y.A. Petrovich, Stomatologiya, 4, 79 (1987)

27. O.S. Gileva, Y.A. Petrovich, Voprosi pitaniya, 5, 9 (1988)

28. O.S. Gileva, E.N. Smirnova, A.A. Pozdnyakova, O.V. Pozdeeva, T.V. Libik, L.Y. Satyukova, I.N. Khalyavina, E.A. Gorodilova, T.Y. Shilova, N.V. Gibadullina, V.A. Sadilova, E.D. Nazukin, Perm Medical Journal, 29(6), 18-24 (2012)

29. O.S. Gileva, Dental Forum, 75(4), 26-27 (2019)

30. I.N. Khalyavina, O.S. Gileva, T.V. Libik, S.V. Koshkin, E.A. Kuklina, N.S. Kuklin, Endodontology Today, 17(3), 13-16 (2019)

31. F.Y. Daurova, I.M. Makeeva, O.S. Gileva, M.K. Makeeva, Z.S. Khabadze, E.S. Kodzaeva, Oral mucosa diseases (Moscow: People's Friendship University of Russia, 2019)

32. Y. Hassona, C. Scully, M. Abu Ghosh, Z. Khoury, S. Jarrar, F. Sawair, Int. Dent. J., 65(1), 15-21 (2015) doi:10.1111/idj.12140

33. S.A. Al-Maweri, W.A. Al-Soneidar, E. Dhaifullah, E.S. Halboub, B. Tarakji, J. Cancer Educ., 32(2), 308-313 (2017) doi:10.1007/s13187-015-0924-y

34. T.M. Babiker, K.A. Osman, S.A. Mohamed, M.A. Mohamed, H.M. Almahdi, BMC Oral Health, 17(1), 69 (2017) doi:10.1186/s12903-017-0351-Z

35. Y.S. Wimardhani, S. Warnakulasuriya, G.P. Subita, A.I. Soegyanto, S.A. Pradono, N. Patoni, J. Investig. Clin. Dent., 10(1), e12379 (2019) doi:10.1111/jicd.12379

36. O.S. Gileva, T.V. Libik, E.V. Kazanceva, E.S. Kodzaeva, Dental Forum, 75(4), 28-29 (2019)

37. D. Bajracharya, S. Gupta, M. Sapkota, S. Bhatta, J. Nepal Health Res. Counc., 15(3), 247-251 (2018) doi:10.3126/jnhrc.v15i3.18849

38. N.S. Prado, R.F. Bonan, A.C. Leonel, U.F. Castro, E.J. Carvalho, F.M. Silveira, D.E. Perez, Med. Oral Patol. Oral Cir. Bucal., 25(1), e89-e95 (2020) doi:10.4317/medoral.23207

39. B. Srikanth Reddy, D. Doshi, M. Padma Reddy, S. Kulkarni, A. Gaffar, V. Ram Reddy, J. Craniomaxillofac. Surg., 40(6), 521-524 (2012) doi:10.1016/j.jcms.2011.09.002

40. N. Shimpi, M. Jethwani, A. Bharatkumar, P.H. Chyou, I. Glurich, A. Acharya, BMC Oral Health, 18(1), 86 (2018) doi:10.1186/s12903-018-0539-x

41. J. Formosa, R. Jenner, M.D. Nguyen-Thi, C. Stephens, C. Wilson, A. Ariyawardana, Asian Pac. J. Cancer. Prev., 16(10), 4429-4434 (2015) doi:10.7314/apjcp.2015.16.10.4429

42. Q. Alkhubaizi, M.E. Khalaf, H. Dashti, P.N. Sharma, J. Int. Soc. Prev. Community Dent., 8(6), 553-559 (2018) doi:10.4103/jispcd.JISPCD_197_18 
43. S.M. Razavi, B. Tahani, S. Nouri, A. Khazaei, Asian Pac. J. Cancer Prev., 16(13), 54395444 (2015) doi:10.7314/apjcp.2015.16.13.5439

44. A.D. Kaprin, V.V. Starinskii, G.V. Petrova, Malignancies in Russia in 2018 (prevalence and mortality) (Moscow: MNIOI n.a. P.A. Gerzen, 2019) URL: https://oncologyassociation.ru/files/medstat/2018.pdf 